\title{
Involvement of Endothelium-derived Relaxing Factor in the Pressure Control of Renin Secretion from Isolated Perfused Kidney
}

Holger Scholz and Armin Kurtz

Institut für Physiologie der Universität Regensburg, D(W)-8400 Regensburg, Germany

\begin{abstract}
Using isolated rat kidneys perfused at controlled pressure, we examined a potential role of endothelium-derived relaxing factor (EDRF) in the pressure control of renin secretion. We found that stimulation of EDRF release by acetylcholine (1 $\mu \mathrm{mol} /$ liter ) increased mean perfusate flow rates from $15.0 \pm 0.5$ to $18.0 \pm 0.5 \mathrm{ml} / \mathrm{min}$ per $\mathrm{g}$ and average renin secretion rates from 3.5 \pm 0.5 to $16.0 \pm 2.0 \mathrm{ng}$ angiotensin $I / \mathrm{h}$ per $\mathrm{min}$ per $\mathrm{g}$ at a perfusion pressure of $100 \mathrm{mmHg}(\operatorname{mean} \pm \mathrm{SEM}, n=6)$. Those effects of acetylcholine were significantly reduced during inhibition of EDRF formation with $N^{\mathrm{G}}$-nitro-L-arginine $(100 \mu \mathrm{mol} /$ liter ), but they were not affected with the cyclooxygenase inhibitor indomethacin ( $10 \mu \mathrm{mol} /$ liter $)$.

Lowering of the perfusion pressure from $100 \mathrm{mmHg}$ to 40 $\mathrm{mmHg}$ resulted in an increase of average renin secretion rates from 3.5 \pm 0.5 to $79 \pm 12 \mathrm{ng} \mathrm{AngI/h}$ per min per $\mathrm{g}$ under control conditions $(n=8)$, and to $171 \pm 20 \mathrm{ng}$ AngI/h per min per $\mathrm{g}$ in the presence of $10 \mu \mathrm{mol} /$ liter acetylcholine $(n=3)$. The rise of renin secretion in response to a reduction of the renal artery pressure was markedly attenuated with inhibitors of EDRF formation such as $N^{G}$-nitro-L-arginine $(100 \mu \mathrm{mol} /$ liter $)$ and related compounds. During inhibition of EDRF formation, addition of sodium nitroprusside (10 $\mu \mathrm{mol} /$ liter) increased mean perfusate flow rates from $12.0 \pm 0.5$ to $23.0 \pm 2.0 \mathrm{ml} / \mathrm{min}$ per $\mathrm{g}$ and average renin secretion rates from $2.0 \pm 0.5$ to $18.0 \pm 1.5 \mathrm{ng}$ AngI/h per min per $\mathrm{g}$ at $100 \mathrm{mmHg}(n=5)$. Lowering of the perfusion pressure from $100 \mathrm{mmHg}$ to $40 \mathrm{mmHg}$ under those conditions increased average renin secretion rates to $220 \pm 14 \mathrm{ng}$ AngI / h per min per $g(n=5)$.

Taken together, our findings suggest that EDRF and related activators of soluble guanylate cyclase stimulate renin secretion from isolated kidneys, predominantly at lower perfusion pressure. Moreover, pressure control of renin secretion appears to require the tonical stimulation by intrarenal EDRF. (J. Clin. Invest. 1993.91:1088-1094.) Key words: juxtaglomerular cells $\bullet$ nitro-L-arginine $\bullet$ acetylcholine $\bullet$ sodium nitroprusside $\bullet$ guanylate cyclase
\end{abstract}

\section{Introduction}

Since the first demonstration by Goldblatt and co-workers ( 1 ), it has been well established that the intrarenal perfusion pres-

Address Correspondence to Holger Scholz, M.D., Institut für Physiologie I, Universität Regensburg, Postfach 101042, D(W)-8400 Regensburg, Germany.

Received for publication 11 March 1992 and in revised form 15 October 1992.

J. Clin. Invest.

(C) The American Society for Clinical Investigation, Inc.

$0021-9738 / 93 / 03 / 1088 / 07 \quad \$ 2.00$

Volume 91, March 1993, 1088-1094 sure is a main physiological control parameter for renin secretion from the kidneys. Renin that is released from the juxtaglomerular $(\mathrm{JG})^{1}$ cells by regulated exocytosis indirectly increases the blood pressure, and this effect is mediated by the vasoconstricting potency of angiotensin II (2). Thus, pressure control of renin secretion is organized in form of a negative feedback loop with the amount of renin released from the kidneys correlating inversely with the intrarenal arterial pressure $(2,3)$.

The renin producing JG cells are located in the wall of the afferent arterioles and a board of indirect evidence suggests that also this so-called "baroreceptor" is installed within the renal vasculature (4-6). The subcellular signaling pathways, however, along which the renal artery pressure modulates renin secretion are not yet understood. One hypothesis existing about this baroreceptor mechanism suggests a direct effect of the intrarenal pressure on JG cells that is mediated by a pressure-dependent stretch of the JG cell membrane (6). Experimental attempts to prove such a direct pressure effect on renin secretion from JG cells have produced controversial results. While one group demonstrated changes of renin secretion from isolated perfused rabbit afferent arterioles in response to changes of the perfusion pressure (7), others did not report pressure related renin secretion in a similar preparation (8). Nonetheless, these different findings may give some hints for the possible baroreceptor function; a pressure dependence of renin secretion, namely, was only found with a free-flow system allowing concomitant changes of flow in response to changes of the perfusion pressure (7), but not with a stop-flow system permitting modulation of the hydrostatic pressure only (8). Those results could indicate that baroreceptor function requires flow through the afferent arterioles and therefore directing attention towards a possible role of endothelial cells in the pressure control of renin secretion.

Endothelial cells in fact have properties making them suitable for mechanotransduction. For instance they are equipped with ion channels that become activated during increased shear stress $(9,10)$. Moreover, they release vasoactive autacoids such as endothelium-derived relaxing factor (EDRF), which is considered to be nitric oxide (NO) (11), in a flow-dependent fashion $(12,13)$. Recent evidence suggests that the activation of shear stress-sensitive potassium channels is causally involved in the release of EDRF (14). Furthermore, it has been demonstrated that endothelial cells can modulate renin secretion from isolated JG cells in primary culture (15).

Nonetheless, the physiological role of the vascular endothelium in the control of renin secretion is not known. Also the

1. Abbreviations used in this paper: Ang, angiotensin; ANP, atrial natriuretic peptide; D-NNA, $N^{\mathrm{G}}$-nitro-D-arginine; EDRF, endothelium-derived relaxation factor; GFR, glomerular filtration rate; JG, juxtaglomerular (cells); L-NAME, nitro-L-argininemethylester; L-NNA, $N^{\mathrm{G}}$ nitro-L-arginine; NMMA, $N^{\mathrm{G}}$-monomethylarginine; NO, nitric oxide; $\mathrm{RSR}$, renin secretion rate; SNP, sodium nitroprusside. 
effect of EDRF on renin secretion is not unequivocal. There are indirect observations, suggesting either a stimulatory (15) or an inhibitory effect of EDRF on renin release in vitro (16).

In view of this background, it appeared reasonable to us to examine a possible physiological role of EDRF in the regulation of renin secretion, in particular, in the control of renin release by the renal perfusion pressure. To this end, we have systematically examined to what extent stimulation or inhibition of EDRF formation modulates the pressure dependence of renin secretion from isolated perfused rat kidneys. We used the model of isolated rat kidneys perfused at controlled pressure because we have previously found that the amount of renin released from this preparation correlates inversely with the renal artery pressure and also the basic mechanisms of myogenic autoregulation are preserved under those conditions (17).

\section{Methods}

Isolated perfused rat kidney. Male SIV strain rats (250-350 g body wt) having free access to commercial pellet chow and tap water were obtained from the local animal house and used throughout. Kidney perfusion was performed in a recycling system according to the technique of Schurek and Alt (18) with minor modifications as described previously (19). In brief, the animals were anesthetized with $150 \mathrm{mg} / \mathrm{kg}$ of 5-ethyl-( 1'-methyl-propyl)-2-thio-barbituric acid (Inactin ${ }^{\circledR} ;$ BYK Gulden, Konstanz, Germany). Volume loss during the preparation was substituted by intermittent injections of physiologic saline $(\sim 2.5$ $\mathrm{ml}$ totally) via a catheter which was inserted into the jugular vein. After opening of the abdominal cavity by a midline incision the right kidney was exposed and placed in a thermostatically controlled metal chamber. The right ureter was cannulated with a small polypropylene tube (PP-10) that was connected to a larger polyethylene catheter (PE50; Labotrade, Schönenbuch, Switzerland). After intravenous heparin injection ( $2 \mathrm{U} / \mathrm{g} \mathrm{Liquemin}^{\otimes}$; Roche, Basel, Switzerland) the aorta was clamped distal to the right renal artery and the large vessels branching off the abdominal aorta were ligated. A double-barreled cannula was inserted into the abdominal aorta and placed closely to the origin of the right renal artery. After ligation of the aorta proximal to the right renal artery the aortic clamp was quickly removed and perfusion was started in situ with an initial flow rate of $8 \mathrm{ml} / \mathrm{min}$. The right kidney was excised and perfusion at constant pressure $(100 \mathrm{mmHg}$ ) was established. To this end, the renal artery pressure was monitored through the inner part of the perfusion cannula (Statham transducer P $10 \mathrm{EZ}$ : Gould, Spectramed Ltd., Coventry, UK) and the pressure signal was used for feedback control of a peristaltic pump. The perfusion circuit was closed by draining the renal venous effluent via a metal cannula back into a reservoir $(200-220 \mathrm{ml})$. The basic perfusion medium, which was taken from the thermocontrolled $\left(37^{\circ} \mathrm{C}\right)$ reservoir, consisted of a modified Krebs-Henseleit solution containing all physiologic amino acids except $\mathrm{L}$-arginine in concentrations between 0.2 and 2.0 $\mathrm{mM}$, and $8.7 \mathrm{mM}$ glucose, $0.3 \mathrm{mM}$ pyruvate, $2.0 \mathrm{mM}$ L-lactate, 1.0 $\mathrm{mM} \alpha$-ketoglutarate, $1.0 \mathrm{mM} \mathrm{L}$-malate, $6.0 \mathrm{mM}$ urea, and $1 \mathrm{mU} / 100$ $\mathrm{ml}$ vasopressin 8-lysine. The perfusate was supplemented with $6 \mathrm{~g} / 100$ $\mathrm{ml} \mathrm{BSA}$ and with freshly washed human red blood cells ( $10 \pm 2 \%$ hematocrit ). Ampicillin $(3 \mathrm{mg} / 100 \mathrm{ml})$ and flucloxacillin $(3 \mathrm{mg} / 100 \mathrm{ml})$ were added to inhibit possible bacterial contamination of the medium. To improve the functional preservation of the preparation, the perfusate was continuously dialysed against a 25 -fold volume of the same composition but without containing erythrocytes and albumin. For oxygenation of the perfusion medium the dialysate was gassed with a $95 \%$ oxygen $/ 5 \%$ carbon dioxide mixture. Perfusate flow rate was obtained from the revolutions of the peristaltic pump that was calibrated before and after each experiment. Renal flow rate and perfusion pressure were continuously monitored by a potentiometric recorder (Kipp \& Zonen, Delft, Netherlands). Stock solutions of the drugs to be tested (see below) were dissolved in freshly prepared perfusate and infused into the arterial limb of the perfusion circuit directly before the kidneys (peristaltic pump 2132 Microperpex $^{\circledR}$; LKB, Bomma, Sweden) at $1 \%$ of the rate of perfusate flow. For determination of perfusate renin activity (pRA) aliquots $(100 \mu \mathrm{l})$ were drawn from the arterial limb of the circulation and the renal venous effluent, respectively. The samples were centrifuged $\left(4^{\circ} \mathrm{C}\right.$ ) at $1,500 \mathrm{~g}$ for $15 \mathrm{~min}$ (Sorvall RT 6000; Sorvall) and the supernatants were stored at $-20^{\circ} \mathrm{C}$ until assayed for renin activity.

Determination of renin activity. Perfusate samples were incubated for $1.5 \mathrm{~h}$ at $37^{\circ} \mathrm{C}$ with plasma of bilaterally nephrectomized male rats as renin substrate (20). The generated angiotensin I was determined by radioimmunoassay (Medipro AG, Teufen, Switzerland).

Renin release. In a previous study performed with the same experimental model, we have found that renin is not inactivated during its passage through isolated perfused rat kidneys (19). Therefore, renin secretory rates were calculated from the arteriovenous differences of perfusate renin activity and the corresponding renal flow rates.

Chemicals. Acetylcholine, L-arginine, $N^{\mathrm{G}}$-nitro-L-arginine, nitro-Largininemethylester, sodium nitroprusside, 8-bromo-cGMP, rat synthetic atrial natriuretic peptide, indomethacin, and isoproterenol were purchased from Sigma International. $N^{\mathrm{G}}$-monomethylarginine and $N^{\mathrm{G}}$-nitro-D-arginine were obtained from Calbiochem (Lucerne, Switzerland) and from Serva (Heidelberg, Germany), respectively.

Presentation of results. Graphs showing renal perfusate flow and renin secretion rates are exact redrawings from original traces. All experiments were performed according to standard protocols and each point represents the mean of $n$ experiments. Perfusate samples for determination of renin activity were collected in 2-min intervals and this is indicated $(O)$ in Figs. 2-6. Asterisks indicate the first value being significant vs. controls.

Statistical analysis. The same kidneys were first taken as controls and were then used for the experimental protocols. Levels of significance were calculated using paired Student's $t$ test. $P<0.05$ was considered significant.

\section{Results}

Basal perfusate flow rates through the isolated rat kidneys perfused at $100 \mathrm{mmHg}$ were $15.0 \pm 0.5 \mathrm{ml} / \mathrm{min}$ per $\mathrm{g}$ (mean $\pm \mathrm{SEM} ; n=15$ ) and basal renin secretion rates were $3.5 \pm 0.5 \mathrm{ng}$ Angiotensin I (AngI)/h per min per $\mathrm{g}(n=15)$.

To obtain first evidence whether EDRF modulates renin secretion from whole kidneys at all, the hormone acetylcholine, which is a well-known activator of endothelial EDRF release (21), was added to the perfusate. Acetylcholine used in the concentration range between $10 \mathrm{nmol} /$ liter and $1 \mu \mathrm{mol} /$ liter caused a dose dependent increase of perfusate flow rate and also led to a graded stimulation of renin secretion at a perfusion pressure of $100 \mathrm{mmHg}$ (Fig. 1). At a concentration of $1 \mu \mathrm{mol} /$ liter acetylcholine, renin secretion rates were increased from the basal level of $3.5 \pm 0.5$ to $16.0 \pm 2.0 \mathrm{ng} \mathrm{AngI} / \mathrm{h}$ per min per $\mathrm{g}(n=6)$. In parallel, urine flow rates increased from $71 \pm 14 \mu \mathrm{l} / \mathrm{min}$ per $\mathrm{g}$ under control conditions to maximally $159 \pm 30 \mu \mathrm{l} / \mathrm{min}$ per $\mathrm{g}$ with $1 \mu \mathrm{mol} /$ liter acetylcholine $(n$ $=6)$.

$N^{\mathrm{G}}$-nitro-L-arginine (L-NNA; $100 \mu \mathrm{mol} /$ liter), an inhibitor of EDRF formation (22), significantly reduced the renal vascular relaxation and abolished the enhancement of renin secretion produced by acetylcholine $(1 \mu \mathrm{mol} / \mathrm{liter})$. Within the same kidneys the vasodilating and renin stimulatory effect of acetylcholine could be partially restored by removing L-NNA from the perfusion medium and by adding $1 \mathrm{mmol} /$ liter of L-arginine (Fig. 2).

EDRF is considered to act in its target cells by activating the soluble guanylate cyclase and thereby increasing the cellular 


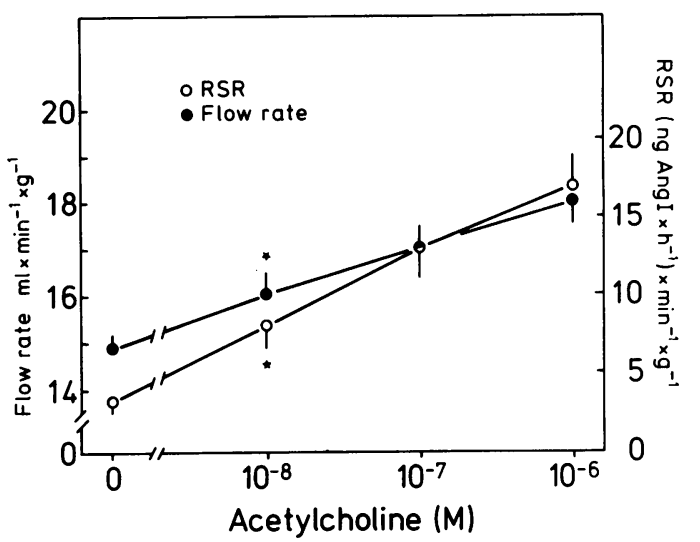

Figure 1. Perfusate flow rates and renin secretion rates in isolated rat kidneys perfused at a constant pressure of $100 \mathrm{mmHg}$ in the presence of graded concentrations of acetylcholine. Data are means \pm SEM of six kidneys. Asterisks indicate $P<0.05$ vs. control.

cyclic GMP levels (23). We therefore assessed the effect of atrial natriuretic peptide (ANP), which is an activator of particulate guanylate cyclase (24) on renin secretion from our preparations. As shown in Table I, ANP ( $100 \mathrm{pmol} /$ liter, and 1 $\mathrm{nmol} /$ liter) led to a dose dependent increase of renin secretion rates to maximal values of $11.0 \pm 3.0 \mathrm{ng} \mathrm{AngI} / \mathrm{h}$ per min per $\mathrm{g}$ $(n=5)$. At both concentrations used, ANP did not change perfusate flow through the kidneys. Also, the membrane permeable cyclic GMP analogue 8-bromo-cyclic GMP ( $100 \mu \mathrm{mol} /$ liter) significantly increased renin secretion rates to $12.0 \pm 2.5$ $\mathrm{ng} \mathrm{AngI/h}$ per min per $\mathrm{g}(n=3)$. For comparison, addition of $10 \mathrm{nmol} /$ liter isoproterenol, which stimulates renin release through a cyclic AMP dependent mechanism (2), resulted in renin secretion rates of $55.0 \pm 5.0 \mathrm{ng} \mathrm{AngI} / \mathrm{h}$ per min per $\mathrm{g}$ $(n=5)$.

Since acetylcholine not only enhances EDRF formation in endothelial cells but also the release of prostacyclin (25), which in turn might stimulate renin secretion (26), we used indomethacin to inhibit prostacyclin synthesis. As shown in Fig. 3, indomethacin $(10 \mu \mathrm{mol} /$ liter $)$ had no significant influence neither on basal flow nor on renin secretion rates. In particular, indomethacin did not affect the vasorelaxing and renin stimulatory effects of acetylcholine (Fig. 3).

A possible role of endogenous EDRF release in the kidneys on pressure-controlled renin secretion was assessed by investigating the effects of three different inhibitors of EDRF formation, namely $N^{\mathrm{G}}$-nitro-L-arginine (L-NNA; $100 \mu \mathrm{mol} /$ liter), nitro-L-argininemethylester (L-NAME; $100 \mu \mathrm{mol} /$ liter) and $N^{\mathrm{G}}$-monomethylarginine (NMMA; $200 \mu \mathrm{mol} /$ liter) on renin secretion. As shown previously, stepwise reductions of the renal artery pressure in the range between $100 \mathrm{mmHg}$ and 40 $\mathrm{mmHg}$ result in exponentially increasing renin secretion rates in this preparation (17). As a standard protocol to stimulate pressure related renin release a single pressure step from 100 $\mathrm{mmHg}$ to $40 \mathrm{mmHg}$ was therefore performed. Under control conditions this maneuver led to an increase of renin secretion from $3.5 \pm 0.5$ to $79 \pm 12 \mathrm{ng} \mathrm{AngI} / \mathrm{h}$ per min per $\mathrm{g}(n=8)$ (Fig. 4). In the presence of L-NNA ( $100 \mu \mathrm{mol} /$ liter $)$, perfusate flow rates significantly decreased from $15.0 \pm 0.5$ to $12.0 \pm 0.5 \mathrm{ml} /$ min per $\mathrm{g}(n=8)$ (Table II) and also renin secretion rates tended to decrease at $100 \mathrm{mmHg}$ (Fig. 4). More clearly, the rise of renin secretion in response to a reduction of the perfusion pressure to $40 \mathrm{mmHg}$ was significantly attenuated in the presence of $100 \mu \mathrm{mol} /$ liter L-NNA ( $13 \pm 3 \mathrm{vs.} 79 \pm 12 \mathrm{ng} \mathrm{AngI} / \mathrm{h}$ per min per $\mathrm{g}$ ). About $50 \%$ of the normal pressure response of renin secretion could be restored by removing L-NNA from the perfusate and by adding $1 \mathrm{mmol} /$ liter of L-arginine (Fig. 4).

To test for the specificity of the effects obtained with LNNA, we also investigated the influence of $N^{\mathrm{G}}$-nitro-D-arginine (D-NNA), a stereoisomer without inhibitory effect on EDRF formation (27). D-NNA ( $100 \mu \mathrm{mol} /$ liter ) did not alter renal flow rates and even slightly improved the pressure response of renin secretion, while L-NNA ( $100 \mu \mathrm{mol} /$ liter $)$ almost blunted the rise of renin release in the same kidneys (Fig. 5). For control, we examined as to whether L-NNA did also affect the renin stimulatory potency of isoproterenol, which activates renin secretion via cyclic AMP formation (2). As shown in Fig. 5, isoproterenol used at a concentration of 10 $\mathrm{nmol} /$ liter, even in the presence of L-NNA and also during D-NNA administration, significantly increased renin secretion rates. Similar to L-NNA, L-NAME, and NMMA, two other inhibitors of EDRF formation, also significantly reduced renin release at a renal artery pressure of $40 \mathrm{mmHg}$ (Table II). On a molar basis, L-NNA and NMMA were more potent than LNAME in decreasing renin secretion at a perfusion pressure of $40 \mathrm{mmHg}$ (Table II). Like L-NNA, L-NAME, and NMMA also significantly reduced perfusate flow rates to $13.0 \pm 0.5$ and $12.5 \pm 0.5 \mathrm{ml} / \mathrm{min}$ per $\mathrm{g}(n=3)$, respectively (Table II). All three inhibitors of EDRF formation did not significantly change urine flow rates (Table II).

Assuming that a fall of the renal artery pressure requires the release of EDRF to become an effective stimulus for renin release, we tested as to whether pressure related renin secretion could be reestablished by mimicking NO release during inhibited EDRF formation. To this end, we examined pressure-dependent renin secretion in the combined presence of an EDRF inhibitor (L-NNA) and of an exogenous nitrate (sodium nitroprusside [SNP]) that mimicks the action of EDRF. As shown in Fig. 6 , the addition of SNP $(10 \mu \mathrm{mol} /$ liter $)$ in the presence of L-NNA ( $100 \mu \mathrm{mol} /$ liter $)$ led to a prompt increase of perfusate flow rates from $12.0 \pm 0.5$ to $23.0 \pm 2.0 \mathrm{ml} / \min \operatorname{per} \mathrm{g}(n=5)$ and to an increase of renin secretion rates from $2.0 \pm 0.5$ to $18.0 \pm 1.5$ ng AngI/h per min per $\mathrm{g}(n=5)$ at $100 \mathrm{mmHg}$. When the

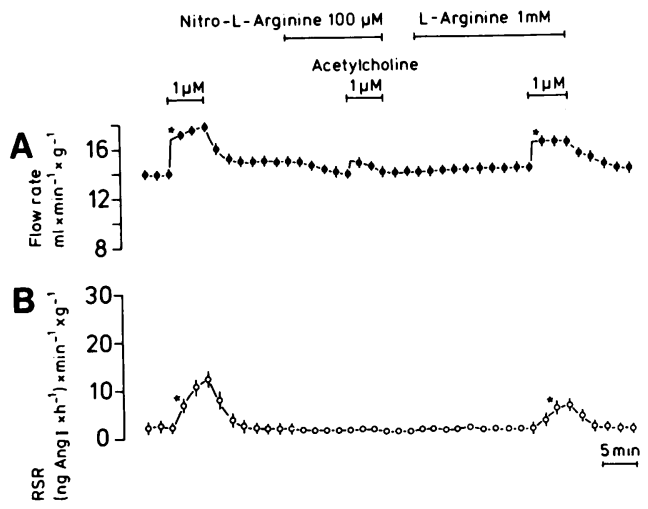

Figure 2. Perfusate flow rates $(A)$ and renin secretion rates $(B)$ in isolated rat kidneys perfused at $100 \mathrm{mmHg}$ in the absence and presence of $1 \mu \mathrm{mol} /$ liter acetylcholine and $100 \mu \mathrm{mol} /$ liter $N^{\mathrm{G}}$-nitro-L-arginine. Each point represents mean $\pm \mathrm{SE}$ of three kidneys. Asterisks indicate the first values being significantly different from control $P$ $<0.05$. 
Table I. Effects of ANP, 8-bromo-cGMP, and Isoproterenol on Renin Secretion Rates (RSR) in Isolated Kidneys Perfused at Constant Pressure of $100 \mathrm{mmHg}$

\begin{tabular}{|c|c|c|c|c|c|}
\hline & Control & ANP & ANP & 8-bromo-cGMP & Isoproterenol \\
\hline & & $100 \mathrm{pmol} / \mathrm{liter}$ & $1 \mathrm{nmol} /$ liter & $100 \mu \mathrm{mol} / \mathrm{liter}$ & $10 \mathrm{nmol} / \mathrm{liter}$ \\
\hline RSR ng Angl/h per min per $g$ & $\begin{array}{c}3.5 \pm 0.5 \\
(5)\end{array}$ & $\begin{array}{c}5.5 \pm 1.0 \\
(3)\end{array}$ & $\begin{array}{c}11.0 \pm 3.0^{*} \\
(5)\end{array}$ & $\begin{array}{c}12.0 \pm 2.5^{*} \\
(3)\end{array}$ & $\begin{array}{c}55.0 \pm 5.0^{*} \\
(5)\end{array}$ \\
\hline
\end{tabular}

The number of experiments is given in parentheses. Data are expressed as $\pm \mathrm{SEM}$. Asterisks indicate $P<0.05$ vs. controls.

perfusion pressure was then reduced to $40 \mathrm{mmHg}$ in the combined presence of L-NNA ( $100 \mu \mathrm{mol} /$ liter ) and SNP $10 \mu \mathrm{mol} /$ liter), renin secretion rates increased to $220 \pm 14 \mathrm{ng} \mathrm{AngI/} \mathrm{h}$ per min per g (Fig. 6).

Finally, we examined whether the pressure dependence of renin secretion was altered under conditions of stimulated EDRF release. To this end, renin secretion rates in the absence and in the presence of acetylcholine were determined in the same kidneys at perfusion pressures of 140, 100, and 40 $\mathrm{mmHg}$. As shown in Fig. 7, acetylcholine used at a concentration of $10 \mu \mathrm{mol} /$ liter significantly altered the relationship between perfusion pressure and renin secretion, in a way that it weakly increased renin release at high pressure and potently enhanced renin secretion at low perfusion pressure: At a renal artery pressure of $140 \mathrm{mmHg}$, acetylcholine $(10 \mu \mathrm{mol} /$ liter $)$ did not significantly affect renin secretion rates, whereas a significant increase of renin release from $3.5 \pm 0.5$ to $17.0 \pm 2.5 \mathrm{ng}$ AngI/h per min per $\mathrm{g}(n=3)$ was obtained at $100 \mathrm{mmHg}$ (Fig. $7)$. When the perfusion pressure was reduced to $40 \mathrm{mmHg}$, renin secretion rates increased to maximal values of $171 \pm 20 \mathrm{ng}$ AngI/h per min per $\mathrm{g}(n=3)$ in the presence of acetylcholine (Fig. 7).

\section{Discussion}

The aim of this study was to investigate a possible involvement of EDRF in the pressure control of renin secretion from the kidneys, which is commonly referred to as the intrarenal baroreceptor mechanism of renin secretion. As an experimental model, we used an isolated rat kidney preparation perfused with a medium containing red blood cells, which is suitable to

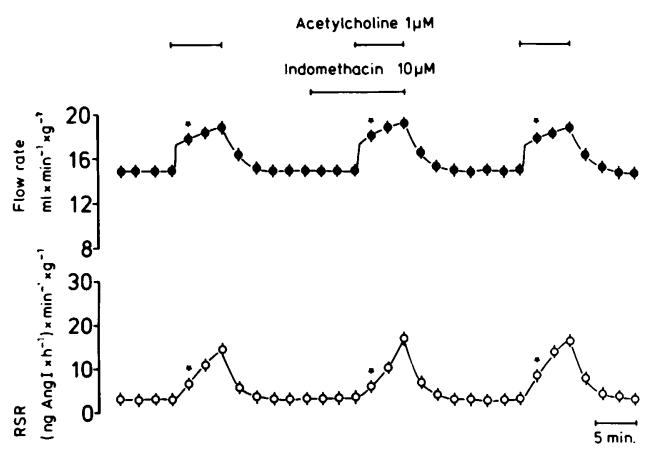

Figure 3. Effect of indomethacin ( $10 \mu \mathrm{mol} / \mathrm{liter})$ on renal flow rates $(A)$ and renin secretion rates $(B)$ in the absence and presence of acetylcholine ( $1 \mu \mathrm{mol} /$ liter $)$. Data are means \pm SEM of five kidneys. Asterisks indicate the first values being significantly different vs. controls $P<0.05$. study the regulation of renin secretion at the organ level (17, 19). In particular, this model displays an inverse relationship between perfusion pressure and renin release (Fig. 7, reference 17 ) in a fashion similar to the in vivo situation (28). Moreover, we have recently demonstrated that the basic mechanisms of myogenic autoregulation of flow are preserved (17) and also characteristic signal transduction mechanisms such as angiotensin II induced inhibition or isoproterenol related stimulation of renin release are operating under those experimental conditions $(17,19)$.

We found that acetylcholine, which activates the formation of endothelial autacoids such as EDRF also in renal vascular beds $(21,29)$, caused a dose dependent decrease in vascular resistance and an increase in renin secretion rates (Fig. 1). Since these effects of acetylcholine were reversibly suppressed in the presence of an established inhibitor of EDRF formation (Fig. 2), it appears most likely that the vasorelaxing and the renin stimulatory action of acetylcholine were both mediated by EDRF. In the same kidney preparations inhibition of prostaglandin synthesis with indomethacin did not affect neither renal vascular relaxation nor the stimulation of renin release caused by acetylcholine (Fig. 3 ) and a possible involvement of prostacyclin in the actions of acetylcholine becomes therefore less likely (30). A vasodilating effect of acetylcholine in the isolated perfused rat kidney is in keeping with previous studies $(31,32)$ as well as with a more general concept indicating a role of the vascular endothelium, particularly of EDRF, in the vasorelaxant action of acetylcholine (33). Stimulation of renin

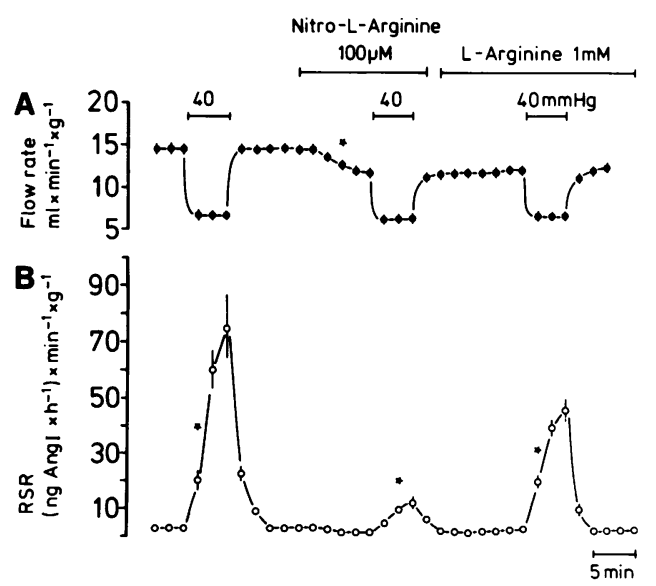

Figure 4. Perfusate flow rates $(A)$ and renin secretion rates $(B)$ in isolated rat kidneys perfused at $100 \mathrm{mmHg}$ and $40 \mathrm{mmHg}$ in the presence of $100 \mu \mathrm{mol} /$ liter $N^{\mathrm{G}}$-nitro-L-arginine or $1 \mathrm{mmol} /$ liter L-arginine. Data are means \pm SEM of eight kidneys. Asterisks indicate the first values being significantly different from controls $P<0.05$. 
Table II. Effects of L-NNA, L-NAME, and NMMA on RSR, Perfusate Flow, and Urine Flow in Isolated Perfused Rat Kidneys

\begin{tabular}{|c|c|c|c|c|}
\hline & Control & L-NNA & L-NAME & NMMA \\
\hline & & $100 \mu \mathrm{mol} / \mathrm{liter}$ & $100 \mu \mathrm{mol} / \mathrm{liter}$ & $200 \mu \mathrm{mol} / \mathrm{liter}$ \\
\hline $\begin{array}{l}\text { RSR ng Angl/h per min per } g \\
\text { at } 40 \mathrm{mmHg}\end{array}$ & $79 \pm 12(8)$ & $13 \pm 3^{*}(8)$ & $31 \pm 6^{*}(3)$ & $10 \pm 2 *(3)$ \\
\hline $\begin{array}{l}\text { Flow rate } \mathrm{ml} / \mathrm{min} \text { per } \mathrm{g} \\
\text { at } 100 \mathrm{mmHg}\end{array}$ & $15.0 \pm 0.5(8)$ & $12.0 \pm 0.5^{*}(8)$ & $13.0 \pm 0.5^{*}(3)$ & $12.5 \pm 0.5^{*}(3)$ \\
\hline $\begin{array}{l}\text { Urine flow } \mathrm{ml} / \mathrm{min} \text { per } \mathrm{g} \\
\text { at } 100 \mathrm{mmHg}\end{array}$ & $71 \pm 14(8)$ & $68 \pm 5(8)$ & $77 \pm 10(3)$ & $75 \pm 7(3)$ \\
\hline
\end{tabular}

The number of experiments is given in parentheses. Data are means \pm SEM. Asterisks indicate $P<0.05$ vs. control.

release by acetylcholine has previously been reported for dogs (34) and turtles (35). A stimulatory effect of EDRF on renin secretion is also supported by our finding that inhibition of EDRF synthesis led to a decrease of basal renin release (Fig. 2). This observation is in good accordance with a recent study reporting that renin secretion from isolated rat kidneys perfused at a constant renal artery pressure of $80 \mathrm{mmHg}$ was significantly reduced with nitro-L-arginine, an inhibitor of EDRF formation (36). A similar finding was made in anesthetized dogs in which blockade of NO synthase caused a decrease of plasma renin activity (37). A stimulatory effect of EDRF on renin secretion is also supported by our recent cell coculture study with isolated juxtaglomerular cells and vascular endothelial cells (15), but it is at variance with another in vitro study performed on kidney slices and suggesting an inhibitory action of EDRF on renin release (16).

In view of the latter discrepancy, it must be considered that acetylcholine induced stimulation of renin secretion as observed in this study was possibly related to changes of flow or was mediated by the macula densa mechanism rather than being caused by a direct stimulatory effect of EDRF on JG cells. However, since acetylcholine increased renin release predominantly at lower pressure values without affecting renal flow rates in this pressure range (Fig. 7), the stimulation of

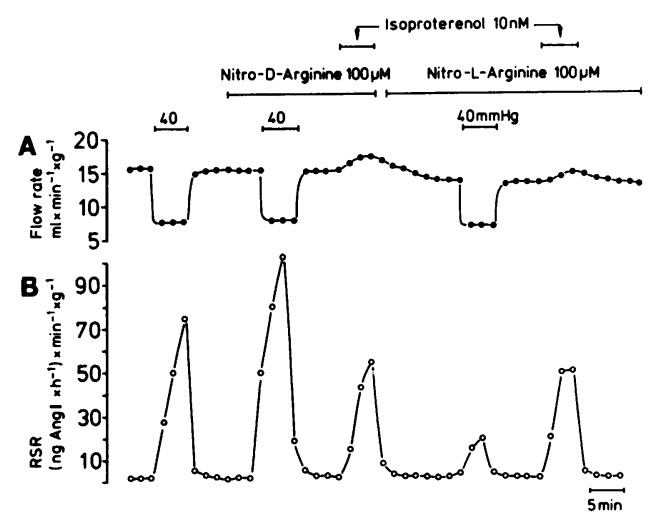

Figure 5. Perfusate flow rates $(A)$ and renin secretion rates $(B)$ in an isolated rat kidney perfused at 100 and $40 \mathrm{mmHg}$ in the presence of $100 \mu \mathrm{mol} /$ liter $N^{\mathrm{G}}$-nitro-D-arginine or $100 \mu \mathrm{mol} /$ liter $N^{\mathrm{G}}$-nitro-L-arginine. In the presence of both drugs, renin secretion was stimulated by $10 \mathrm{nmol} /$ liter isoproterenol. The combination of experiments shown in this figure was done with two kidneys, which produced very similar results. Original redrawing from the recordings of one of these experiments is shown. renin secretion in response to acetylcholine was probably not mediated by parallel changes of flow. Moreover, acetylcholine also significantly increased urine flow rates at a perfusion pressure of $100 \mathrm{mmHg}$, and if there was an effect on glomerular filtration rate (GFR) at all, one should therefore expect that acetylcholine enhanced rather than decreased GFR (32). As a consequence, the tubular sodium chloride delivery should if at all increase, thereby causing inhibition rather than a stimulation of renin secretion via the macula densa mechanism (38).

A major pathway along which EDRF exerts its cellular effects is via stimulation of soluble guanylate cyclase activity leading to a rise of intracellular cGMP levels (23). The role of cGMP in the control of renin secretion is not yet unequivocally understood. Membrane permeable cGMP analogues such as 8-bromo-cGMP have been found either to inhibit renin release from kidney slices (39) and from cultured JG cells $(39,40)$ or to have no effect on renin secretion from kidney slices (41) and isolated perfused kidneys (42). Also experiments with ANP, an activator of particulate guanylate cyclase (24), have produced divergent results. Thus, ANP has been found to inhibit (39) or to stimulate (41) renin secretion in vitro from kidney slices and to decrease renin release from cultured JG cells (43) and in vivo upon systemic application (44). Intrarenal infusion of ANP into conscious dogs (45), as well as application of ANP into isolated perfused rat kidneys (46), however, has been observed to stimulate renin release. The findings obtained in this study would suggest that an increase of renal cGMP levels has a stimulatory rather than an inhibitory effect on renin secretion. Whether this effect is due to a direct action of cGMP in JG cells

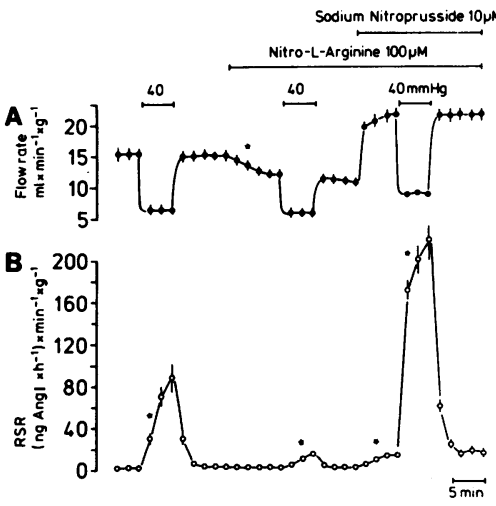

Figure 6. Perfusate flow rates $(A)$ and renin secretion rates $(B)$ in isolated rat kidneys perfused at 100 and 40 $\mathrm{mmHg}$ in the absence and presence of 100 $\mu \mathrm{mol} /$ liter $N^{\mathrm{G}}$-nitro-L-arginine and in the combined presence of $100 \mu \mathrm{mol} /$ liter $N^{\mathrm{G}}$-nitro-L-arginine and $10 \mu \mathrm{mol} /$ liter SNP. Data are means \pm SEM of five kidneys. Asterisks indicate the first values being significantly different vs. controls $P<0.05$. 


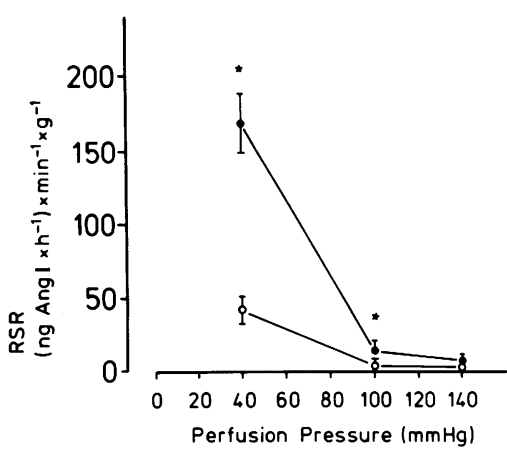

the presence of acetylcholine in the same kidneys. Data are means \pm SE of three kidneys. Asterisks indicate $P<0.05$ vs. absence of acetylcholine. $\bigcirc$, Control; $\bullet$, acetylcholine $(10 \mu \mathrm{M})$.

or indirectly mediated by other cells cannot be distinguished from our experiments with whole kidneys. It is also possible that the stimulatory effect of EDRF on renin secretion was not related to cGMP formation because there is accumulating evidence for biologic effects of EDRF/NO that are not linked to cGMP formation $(47,48)$.

Irrespective of the molecular mechanism by which EDRF enhances renin secretion from whole kidneys, our findings also show that the enhancement of renin release from the kidneys in response to a reduction of the perfusion pressure was almost blunted in the presence of drugs (Fig. 4, Table II), that are commonly considered to inhibit EDRF formation (13, 22, 49, 50 ). The following lines of evidence support the specific action of these inhibitors of EDRF synthesis on renin release: Firstly, the effects of L-NNA and related compounds could partially be reversed by the addition of higher concentrations of $\mathrm{L}$-arginine (Figs. 2 and 4) which is an established maneuver to restore inhibited EDRF formation (49). Secondly, nitro-D-arginine, a stereoisomer of nitroarginine, which is presumed not to block EDRF synthesis (27), also did not attenuate the pressure dependence of renin secretion (Fig. 5). Thirdly, the stimulatory effect of isoproterenol, which directly enhances renin secretion by increasing cellular cAMP levels (2) was not influenced during inhibition of EDRF formation (Fig. 5). Finally, substitution of EDRF by an artificial analogue, such as SNP reestablished the pressure dependence of renin secretion, even in the presence of inhibitors of EDRF synthesis (Fig. 6).

Taken together, we infer from our findings that EDRF is a stimulatory signal for renin secretion in the kidneys, and we suggest that tonically released EDRF accounts for the rise of renin secretion caused by a fall of the perfusion pressure.

The question arises as to whether the typical inverse relationship between renin secretion and renal artery pressure results from a pressure-dependent formation of EDRF, in a way that EDRF release is low at high pressure and high at low pressure. Another possibility would be that the release of EDRF is less pressure dependent, but that the stimulatory effect of EDRF on renin secretion is counterbalanced by a second pressure related process. We attempted to distinguish between both possibilities by assaying cGMP in the venous renal effluent as an indirect measure for renal EDRF activity. However, cGMP concentrations in the perfusate were below the detection limit of the radioimmunoassay used $(<25 \mathrm{fmol} / \mathrm{ml})$, thus allowing no information about pressure dependent formation of EDRF in the kidneys.

Nonetheless, we think that there are two lines of indirect evidence suggesting that the effect of EDRF on renin secretion from JG cells rather than the formation of EDRF itself was controlled by the perfusion pressure. Thus, acetylcholine produced a potent EDRF dependent vasodilation at $100 \mathrm{mmHg}$ (Fig. 2), indicating that the release of higher quantities of EDRF can principally occur in this pressure range. At the same time there was only a relatively weak EDRF dependent stimulation of renin secretion at $100 \mathrm{mmHg}$, but a powerful increase of renin release with decreasing perfusion pressure (Fig. 7). Similarly, mimicking the effect of EDRF on soluble guanylate cyclase activity with SNP markedly decreased vascular resistance but only weakly stimulated renin secretion at $100 \mathrm{mmHg}$ (Fig. 6 ). Similar to acetylcholine the stimulatory effect of SNP on renin secretion became enhanced by lowering the perfusion pressure to $40 \mathrm{mmHg}$ (Fig. 6).

Taken together, our findings are compatible with the concept that the baroreceptor mechanism controlling renin secretion consists of at least two components. A tonical stimulatory one provided by the continuous release of EDRF from the vascular endothelium or from other cellular structures of the kidney. And a second inhibitory one, that is directly related to the perfusion pressure and that is enough potent to neutralize the stimulatory influence of EDRF at higher pressure values.

\section{Acknowledgments}

We wish to thank Marlies Hamann and Karl-Heinz Götz for doing the artwork and Hannelore Trommer for providing expert secretarial help.

This study was in part financially supported by grants from the Swiss National Science Foundation (31-26381.89) and the Deutsche Forschungsgemeinschaft (Ku 859/2-1).

\section{References}

1. Goldblatt, H., J. Lynch, R. F. Hanzel, and J. W. W. Summerville. 1934. The production of persistent elevation of systolic blood pressure by means of renal ischemia. J. Exp. Med. 59:347-380.

2. Hackenthal, E., M. Paul, D. Ganten, and R. Taugner. 1990. Morphology, physiology, and molecular biology of renin secretion. Physial. Rev. 70:10671116.

3. Tobian, L. 1962. Relationship of juxtaglomerular apparatus to renin and angiotensin. Circulation. 25:189-192.

4. Skinner, S. L., J. W. MacCubbin, and I. H. Page. 1964. Control of renin secretion. Circ. Res. 15:64-76.

5. Blaine, E. H., J. O. Davis, and R. L. Prewitt. 1970. Evidence for a renal vascular receptor in control of renin secretion. Am. J. Physiol. 220:1593-1597.

6. Fray, J. C. S. 1977. Stretch receptor model for renin release with evidence from perfused rat kidney. Am. J. Physiol. 231:936-944.

7. Bock, H. A., M. Hermle, A. Fiallo, R. W. Osgood, and T. A. Fried. 1990. Measurement of renin secretion in single perfused rabbit glomeruli. Am. J. Physiol. 258:F1460-F1465.

8. Salomonsson, M., O. Skott, and A. E. G. Persson. 1991. Influence of intraluminal arterial pressure on renin release. Acta. Physiol. Scand. 141:285-286.

9. Lansman, J. B., T. J. Hallam, and T. J. Rink. 1987. Single stretch-activated ion channels in vascular endothelial cells as mechano-transducers. Nature (Lond.). 325:811-813.

10. Oleson, S. P., D. E. Clapham, and P. F. Davies. 1988. Hemodynamic shear stress activates a $\mathrm{K}^{+}$current in vascular endothelial cells. Nature (Lond.). 331:168-170.

11. Palmer, R. M. J., A. G. Ferrige, and S. Moncada. 1987. Nitric oxide release accounts for the biological activity of endothelium derived relaxing factor. Nature (Lond.). 327:524-527.

12. Rubanyi, G. M., J. C. Romero, and P. M. Vanhoutte. 1986. Flow-induced release of endothelium-derived relaxing factor. Am. J. Physiol. 250:H1145H1149.

13. Cooke, J. P., J. S. Stamler, N. Andon, P. R. Davies, and J. Loscalzo. 1990. 
Flow stimulates endothelial cells to release a nitrovasodilator that is potentiated by reduced thiol. Am. J. Physiol. 28:H804-H812.

14. Cooke, J. P., E. Rossitch, N. A. Andon, J. Loscalzo, and V. Dzau. 1991. Flow activates an endothelial potassium channel to release an endogenous nitrovasodilator. J. Clin. Invest. 88:1663-1671.

15. Kurtz, A., B. Kaissling, R. Busse, and W. Baier. 1991. Endothelial cells modulate renin secretion from isolated mouse juxtaglomerular cells. J. Clin. Invest. 88:1147-1154.

16. Vidal, M. J., J. C. Romero, and P. M. Vanhoutte. 1988. Endothelium-derived relaxing factor inhibits renin release. Eur. J. Pharmacol. 149:401-402.

17. Scholz, H., and A. Kurtz. 1992. Disparate effects of calcium channel blockers on pressure-dependence of renin secretion and flow in the isolated perfused rat kidney. Eur. J. Physiol. 421:155-162.

18. Schurek, H. J., and M. Alt. 1981. Effect of albumin on the function of perfused rat kidney. Am. J. Physiol. 240:F569-F576.

19. Scholz, H., B. Kaissling, T. Inagami, and A. Kurtz. 1991. Differential response of renin secretion to vasoconstrictors in the isolated perfused rat kidney. J. Physiol. (Lond.). 441:453-468.

20. Kurtz, A., J. Pfeilschifter, A. Hutter, C. Bührle, R. Nobiling, R. Taugner, E. Hackenthal, and C. Bauer. 1986. Role of protein kinase $C$ in the inhibition of renin release caused by vasoconstrictors. Am. J. Physiol. 250:C563-C571.

21. Kon, V., R. C. Harris, and I. Ichikawa. 1990. A regulatory role for large vessels in organ circulation. J. Clin. Invest. 85:1728-1733.

22. Moore, P. K., O. A. al-Swayeh, N. W. S. Chong, R. A. Ewans, and A. Gibson. 1990. L- $N^{\mathrm{G}}$-nitro arginine (L-NOARG), a novel, L-arginine-reversible inhibitor of endothelium-dependent vasodilation in vitro. Br. J. Pharmacol. 99:408-412.

23. Katsuki, S., W. Arnoöd, C. Mittal, and F. Murad. 1977. Stimulation of guanylate cyclase by sodium nitroprusside, nitroglycerine and nitric oxide in various preparations and comparison to the effects of sodium azide and hydroxylamine. J. Cyclic Nucleotide Res. 3:23-35.

24. Waldman, S. A., R. M. Rapoport, and F. Murad. 1986. Cyclic guanosine monophosphate as a mediator of vasodilation. J. Clin. Invest. 78:1-5.

25. Vanhoutte, P. M., G. M. Rubanyi, V. M. Miller, and D. S. Houston. 1986. Modulation of vascular smooth muscle contraction by the endothelium. Annu. Rev. Physiol. 48:307-320.

26. Freeman, R. H., J. O. Davis, and D. Villarreal. 1984. Role of renal prostaglandins in the control of renin release. Circ. Res. 54:1-9.

27. Lamontagne, D., U. Pohl, and R. Busse. 1991. $N^{\mathrm{G}}$-nitro-L-arginine antagonizes endothelium-dependent dilator responses by inhibiting endothelium-derived relaxing factor release in the isolated rabbit heart. Pfluegers Arch. 418:266270.

28. Kirchheim, H. R., H. Ehmke, E. Hackenthal, W. Löwe, and P. Persson. 1987. Autoregulation of renal blood flow, glomerular filtration rate and renin release in conscious dogs. Pfluegers Arch. 410:441-449.

29. Cairns, H. S., M. E. Rogerson, J. Westwick, G. H., and J. Neild. 1991. Regional heterogeneity of endothelium-dependent vasodilatation in the rabbit kidney. J. Physiol. (Lond.). 436:421-429.

30. Beierwaltes, W. H., S. Schryver, E. Sanders, J. Strand, and J. C. Romero. 1982. Renin release selectively stimulated by prostaglandin $\mathrm{I}_{2}$ in isolated rat glomeruli. Am. J. Physiol. 243:F276-F283.

31. Bhardway, R., and P. K. Moore. 1989. The effect of arginine and nitric oxide on resistance blood vessels of the perfused rat kidney. Br. J. Pharmacol. 97:739-744.
32. Radermacher, J., U. Förstermann, and J. C. Frölich. 1991. Endotheliumderived relaxing factor influences renal vascular resistance. Am. J. Physiol 259:F9-F17.

33. Furchgott, R. F. 1983. Role of endothelium in responses of vascular smooth muscle. Circ. Res. 53:557-573.

34. Ayers, C. R., R. H. J. Harris, and L. G. Lefer. 1969. Control of renin release in experimental hypertension. Circ. Res. 24/25 (Suppl. I)I 103-I 113.

35. Cipolle, M. D., J. E. Zehr, and G. A. Reinhart. 1986. Effects of autonomic agents on renin release in the turtle, pseudemys scripta. Am. J. Physiol. 251:R1103-R1108.

36. Gardes, J., J.-M. Poux, M.-F. Gonzalez, F. Alhenc-Gelas, and J. Menard. 1992. Decreased renin release and constant kallikrein secretion after injection of L-NAME in isolated perfused rat kidney. Life Sci. 50:987-993.

37. Majid, D. S. A., and L. G. Navar. 1992. Suppression of blood flow autoregulation plateau during nitric oxide blockade in canine kidney. Am. J. Physiol. 262:F40-F46.

38. Skott, O., and J. P. Briggs. 1988. Direct demonstration of macula densamediated renin secretion. Science (Wash. DC). 237:1618-1620.

39. Henrich, W. L., E. A. McAllister, P. B. Smith, and W. B. Campbell. 1988. Guanosine 3',5'-cyclic monophosphate as a mediator of inhibition of renin release. Am. J. Physiol. 255:F474-F478.

40. Kurtz, A., R. Della Bruna, J. Pfeilschifter, and C. Bauer. 1988. Role of cGMP as second messenger of adenosine in the inhibition of renin release. Kidney Int. 33:798-803.

41. Hiruma, M. F., F. Ikemoto, and K. Yamamoto. 1986. Rat atrial natriuretic factor stimulates renin release from renal cortical slices. Eur. J. Pharmacol. 125:151-153.

42. Peart, W. S., T. Quesada, and I. Tenyi. 1975. The effects of cyclic adenosine 3'5'-monophosphate and guanosine 3'5'-monophosphate and theophylline on renin secretion in the isolated perfused kidneys of the rat. Br. J. Pharmacol. $54: 55-60$.

43. Kurtz, A., R. Della Bruna, J. Pfeilschifter, R. Taugner, and C. Bauer. 1986. Atrial natriuretic peptide inhibits renin release from isolated renal juxtaglomerular cells by cGMP-mediated process. Proc. Natl. Acad. Sci. USA. 83:47694773.

44. Struthers, A. D., J. V. Anderson, N. Payne, R. C. Causon, J. D. H. Slater, and S. R. Bloom. 1986. The effect of atrial natriuretic peptide on plasma renin activity, plasma aldosterone, and urinary dopamine in man. Eur. J. Clin. Pharmacol. 31:223-226.

45. Ehmke, H., P. B. Persson, A. Just, B. Nafz, M. Seyfarth, and H. R. Kirchheim. 1992. Dual regulation of atrial natriuretic peptide on renin release in conscious dogs. Am. J. Physiol. 263:R529-R536.

46. Hackenthal, E., R. E. Lang, and C. P. Bührle. 1985. Atrial natriuretic factor stimulates renin release from the isolated rat kidney. J. Hypertens. 3(Suppl.):S3232-S325.

47. Garg, U. C., and A. Hassid. 1991. Nitric oxide decreases cytosolic free calcium in BALB/c 3T3 fibroblasts by a cyclic GMP-independent mechanism. $J$. Biol. Chem. 266:9-12.

48. Brüne, B., and E. G. Lapetina. 1989. Activation of a cytosolic ADP-ribosyltransferase by nitric oxide generating agents. J. Biol. Chem. 264:8455-8458.

49. Moncada, S. R., M. J. Palmer, and E. A. Higgs. 1989. Biosynthesis of nitric oxide from L-arginine. Biochem. Pharmacol. 38:1709-1715.

50. Palmer, R. M. J., D. S. Ashton, and S. Moncada. 1988. Vascular endothelial cells synthesize nitric oxide from L-arginine. Nature (Lond.). 333:664-666. 